\title{
Design and test of urea hydrolysis reactor for vehicle
}

\author{
Qi Zhanfeng ${ }^{1}$, Li Shusen ${ }^{1}$ and Guo Xiuli ${ }^{2}$ \\ ${ }^{1}$ Northeast Forestry University, 150040, harbin, China \\ ${ }^{2}$ Dalian University, 116622, Dalian, China
}

\begin{abstract}
Ammonia production technology of urea-SCR system for vehicle is mainly used in pyrolysis. The reaction is complex, and there are some side effects. So a kind of urea hydrolysis device for vehicle is designed. Based on the in-depth analysis of ammonia production technology's mechanism of urea hydrolysis for vehicle, the modified extended UNIQUAC equation and PHS equation of state were used to solve the thermodynamic model, and the experimental verification was carried out on the JX493ZLQ3 diesel engine. The results show that the design of urea hydrolysis reactor is in agreement with the experimental results. In the environment of urea hydrolysis, the higher the hydrolysis temperature, the faster the urea hydrolysis and the faster the production of ammonia. Under the same conditions, the hydrolysis rate of urea was the same, the higher the initial quality, the more ammonia produced. The method is suitable for the ammonia production technology of urea hydrolysis for vehicle and can be used for the formation of urea hydrolysis SCR system.
\end{abstract}

\section{Introduction}

Urea-SCR technology can effectively reduce the emissions of nitrogen oxides in diesel engines, so it is widely used. The preparation method of reducing agent $\mathrm{NH} 3$ in the technology has the urea pyrolysis and urea hydrolysis. The current vehicle SCR system is based on the development of urea pyrolysis technology. The core technology of urea pyrolysis is to inject the urea solution into the high temperature medium. The pyrolysis reaction of urea was decomposed to generate $\mathrm{NH}_{3}, \mathrm{CO}_{2}$ and $\mathrm{H}_{2} \mathrm{O}$ [1]. But because of the vehicle body and SCR volume limit, SCR system cannot achieve complete pyrolysis reaction. So the research focus is mainly on the control strategy of injection. And urea in the pyrolysis process, there will be a certain byproduct, such as isocyanate, melamine, etc.. These reduce the utilization rate of urea and the catalytic effect, and produce a lot of side effects such as urea crystallization.

Urea hydrolysis process is a completely different technical route from the pyrolysis process. The hydrolysis reaction of urea is a side reaction in the process of urea production. In the field of chemical fertilizer, the hydrolysis reaction belongs to the category of deep hydrolysis. It is usually used in the form of a series of cascade. The process flow is complex and the equipment is huge. In the field of denitrification in power plant, the hydrolysis of urea belongs to the category of shallow hydrolysis. It is usually carried out using a pressure vessel. Hydrolysis of urea solution with high concentration was used to generate $\mathrm{NH}_{3}, \mathrm{CO}_{2}$ and $\mathrm{H}_{2} \mathrm{O}$. The urea hydrolysis process for vehicle is used for the preparation of ammonia in the vehicle condition, which is more convenient and economical. Compared with deep hydrolysis in the chemical fertilizer and hydrolysis denitrification in power plant, its operating conditions and process routes were significant difference. Therefore, the research of urea hydrolysis technology of the vehicle will be a brand-new topic.

\section{Design of urea hydrolysis reactor for vehicle}

The structure diagram of the urea hydrolysis device is shown in Figure 1. The reactor utilizes the waste gas heat of diesel engine as an external heat source to carry out the hydrolysis of urea. $\mathrm{NH}_{3}$ is produced and then discharged into the tail gas.

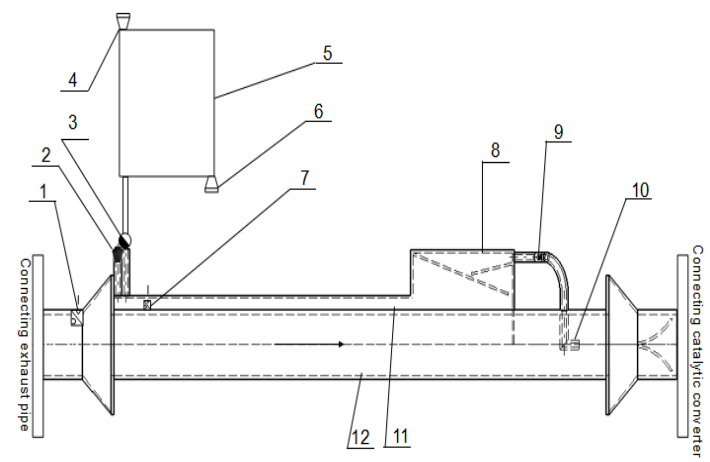

1-Remote thermometer, 2-one-way control valve, 3-metering pump, 4 urea solution inlet, 5-urea storage tank, 6-urea solution outlet, 7-remote liquidometer, 8-gas-liquid separation chamber (plenum chamber), 9ammonia metering valve, 10-product gas outlet, 11-hydrolysis chamber, 12-exhaust pipe

Figure 1. Schematic diagram of the structure of urea SCR hydrolysis reactor for vehicle. 
The hydrolysis system is mainly composed of urea storage tank 11 , hydrolysis chamber 5 , metering pump 3 , gas-liquid separation chamber 8 , ammonia metering valve 9 , product gas outlet 10 , one-way control valve 2 and the corresponding connection pipe.Urea solution inlet 4 and urea solution outlet 6 on the urea storage tank. The whole reactor can be connected with the exhaust pipe and the vehicle SCR catalytic converter. Product gas outlet is right at the center of the exhaust pipe 12 . The reactor is installed remote liquidometer 7 and remote thermometer 1. The urea solution hydrolysis reaction system which is heated by tail gas is used in the vehicle SCR system. The urea solution complete heating, hydrolysis reaction, gas product release, gas-liquid separation, steady flow in the hydrolysis reactor in a series of physical and chemical change.

The test proved [2] that there is oxygen in urea ammonium carbamate solution, make chemical passivation of stainless steel. An oxide film formed on the surface of the stainless steel, especially when used in chrome and nickel stainless steel. They can cause the surface to form a dense oxide film, the corrosion rate is greatly reduced. In order to maintain the formation of the oxide film and make the stainless steel passivation, the oxygen content in the solution is the lowest limit of $10 \times$ $10^{-6}$. So it is necessary to add air to the raw materials. The urea hydrolysis reactor is made of $316 \mathrm{~L}$ double phase stainless steel. And in the design of a one-way control valve to increase the supply of oxygen.

\section{Study on the ammonia production mechanism of urea hydrolysis for vehicle}

The urea hydrolysis system involves $\mathrm{NH}_{3}-\mathrm{CO}_{2}-\mathrm{H}_{2} \mathrm{O}-$ Urea(Ammonia-Carbon dioxide-Water-Urea, ACWU) multicomponent solution system. The thermodynamic equilibrium calculation of the system should take into account both the vapor liquid equilibrium, the ionization equilibrium and the equilibrium of chemical reaction.

Due to high mass fraction of urea hydrolysis process in urea solution of vehicle, ionization can be neglected in liquid phase weak electrolyte. The liquid phase can be reasonably simplified as 4 components of $\mathrm{NH}_{3}, \mathrm{CO}_{2}, \mathrm{H}_{2} \mathrm{O}$ and urea. And the gas phase contains 3 components, including $\mathrm{H}_{2} \mathrm{O}, \mathrm{CO}_{2}$ and $\mathrm{NH}_{3}$. According to the ACWU gas liquid equilibrium system composed of the urea hydrolysis reaction in the reactor, the thermodynamic model and dynamic model are established, and the reaction mechanism is described.

Urea hydrolysis reaction can be expressed as follows. It reflects the relationship between the chemical equilibrium constant and the component.

$$
K_{r}=\frac{x_{\mathrm{CO} 2} \cdot x_{\mathrm{NH} 3}^{2}}{x_{\mathrm{Urea}} \cdot x_{\mathrm{H} 2 \mathrm{O}}} \frac{\gamma_{\mathrm{CO} 2}(T, X) \cdot \gamma_{\mathrm{NH} 3}^{2}(T, X)}{\gamma_{\mathrm{Urea}}(T, X) \cdot \gamma_{\mathrm{H} 2 \mathrm{O}}(T, X)}
$$

In the formula, $x_{\mathrm{i}}$ is the mole fraction of the component, and $\gamma_{i}$ is the activity coefficient of the component, and the $K_{\mathrm{r}}$ is the equilibrium constant of the reaction.
The calculation of activity coefficients of each component was calculated using the extended UNIQUAC equation [3].

In the calculation of vapor liquid equilibrium of ACWU system, according to the properties of $\mathrm{H}_{2} \mathrm{O}, \mathrm{NH}_{3}$ and $\mathrm{CO}_{2}$ and their content in liquid phase, two kinds of different relations of Henry or Raoult are used in the description of the vapor liquid equilibrium of the system. In the liquid phase, a large number of components of $\mathrm{H}_{2} \mathrm{O}$ are found in the liquid phase, and the modified Raoult model is adopted. Component of $\mathrm{NH}_{3}$ and $\mathrm{CO}_{2}$ are easy to be volatile and less in liquid phase. Their reference state of the infinite dilute solution is selected in the water. Their gas phase is subject to the modified relation of Henry's law [4].

Under a certain temperature and time condition the urea hydrolysis reactor is, which causes the urea in urea solution hydrolysis to be ammonia and carbon dioxide. The ammonia gas is discharged into the exhaust pipe through a pressure stabilizing cavity. As the use of exhaust heat as a heat source, temperature and flow rate of the exhaust are not fixed. Therefore, the amount of ammonia obtained from the hydrolysis reaction is not fixed, it must be calculated accurately. The core calculation of urea hydrolysis system is mainly based on the model of urea hydrolysis reactor. The calculation model is combined with the least square method and the Newton method in order to obtain a more accurate approximation and the stability of the convergence. And the above analysis was developed to calculate the program with matlab.

\section{Experiment and result analysis}

The experiment was carried out to verify the thermodynamic and dynamic simulation of the system by means of the test device shown in Figure 2.

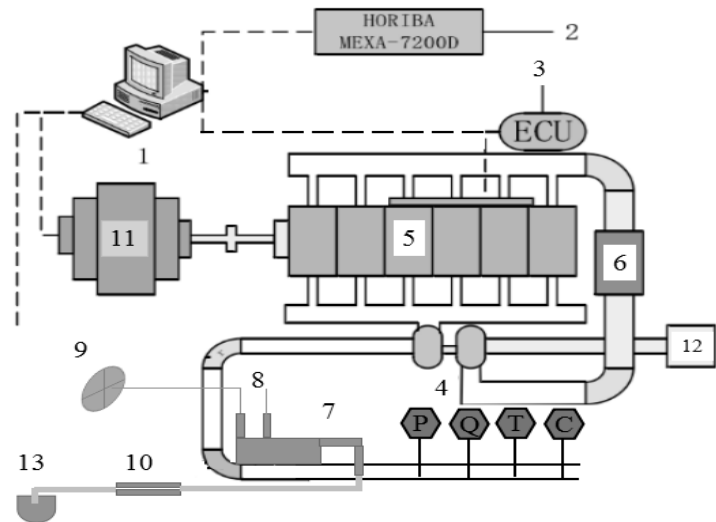

1-calibration computer, 2-gas analyzer, 3-engine ECU, 4-booster, 5diesel engine, 6-cooler, 7-hydrolysis device, 8-urea solution inlet, 9blower, 10-water cooled condenser, 11-dynamometer, 12-air filter, 13boric acid solution, P-pressure sensor, Q-air flow meter, T-temperature sensor, $\mathrm{C}-\mathrm{NO}_{\mathrm{x}}$ sensor

Figure 2. Schematic of engine bench test system.

When the engine reaches a steady state, certain quantity of urea solution is injected into the hydrolysis reactor through urea solution inlet of hydrolysis reactor. With the blower through the air inlet to the hydrolysis 
reactor blowing into the air, gas is generated from the air outlet out. The generated gas through a water condenseris absorbed by a test acid solution that is placed below the water condenser. By changing the reaction conditions of urea hydrolysis, including the hydrolysis temperature and the initial mass, the flow and heat were measured and calculated. The hydrolysis of urea under different conditions was studied. The diesel engine model is JX493ZLQ3, and the basic parameters are shown in Table 1 .

Table 1. Basic parameters of diesel engine.

\begin{tabular}{|c|c|}
\hline $\begin{array}{c}\text { Parameter name / } \\
\text { unit }\end{array}$ & values \\
\hline engine type & $\begin{array}{c}\text { Water cooled, four stroke, } \\
\text { inline, turbocharged inter- } \\
\text { cooling, common rail }\end{array}$ \\
\hline Cylinder & 4 \\
\hline cylinder stroke & $102 \mathrm{~mm}$ \\
\hline bore & $93 \mathrm{~mm}$ \\
\hline displacement & $2.771 \mathrm{~L}$ \\
\hline rated revolutions & $3600 \mathrm{r} / \mathrm{min}$ \\
\hline maximum power & $85 \mathrm{k} \mathrm{W}$ \\
\hline
\end{tabular}

When the influence of the exhaust temperature on the urea hydrolysis, the control of the engine is controlled in 5 different stable conditions. $20 \mathrm{ml}$ urea solution was added to the reactor, and then through the air, urea hydrolysis experiments started. The hydrolysis reaction time was $2 \mathrm{~min}$, and then the samples were analyzed to study the hydrolysis of urea. When the operating conditions change with the exhaust temperature changes, the comparison of the hydrolysis rate and the theoretical value of the urea hydrolysis reactor is shown in Figure 3.

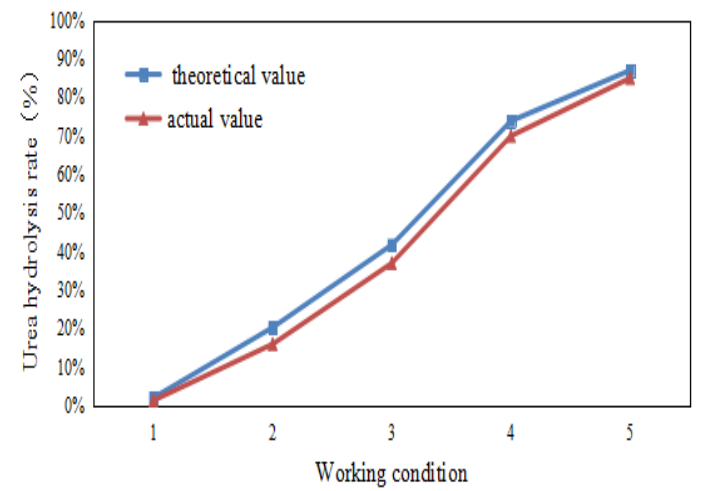

Figure 3. Comparison between theoretical value and experimental value of the rate of urea hydrolysis.

Under the same reaction time, with the increase of the hydrolysis temperature, the hydrolysis rate of urea is increasing, and the hydrolysis rate of urea is positively correlated with the hydrolysis temperature. It can be seen from the figure that the experimental data is always smaller than the theoretical data, and the lower the temperature, the greater the deviation. This is because on the one hand, impurities in the urea solution, will lead to a high value of theoretical calculation. On the other hand, when the temperature is low, the amount of ammonia produced is small, and it is easy to produce large measurement error.

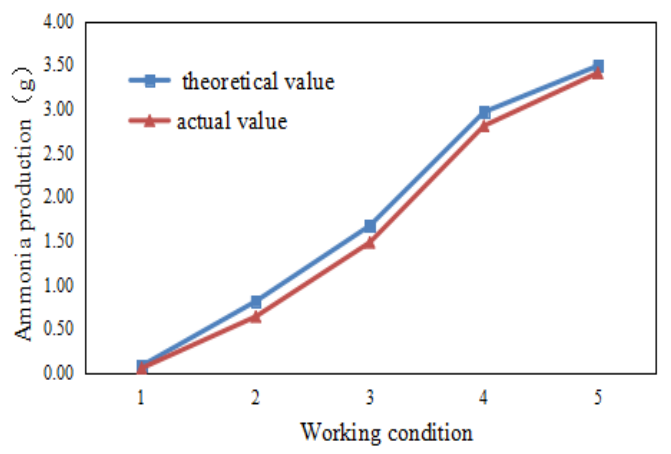

Figure 4. Comparison between theoretical value and experimental value of ammonia production.

As can be seen from Figure 4, the yield of urea hydrolysis and reaction temperature also showed a positive correlation, the higher the hydrolysis temperature, the faster the hydrolysis of urea, the faster the production of ammonia.

When the initial mass of urea hydrolysis is affected by the experiment, it is to control the engine to run in a stable condition. The urea solution of $30 \mathrm{ml}, 20 \mathrm{ml}, 40 \mathrm{ml}$ and $10 \mathrm{ml}$ were added into the hydrolysate, and then the air was added into the reactor to carry out the urea hydrolysis experiment. The hydrolysis reaction time was $2 \mathrm{~min}$, and then the samples were analyzed to study the hydrolysis of urea. Under different conditions, the comparison of the theoretical values is shown in Figure 5.

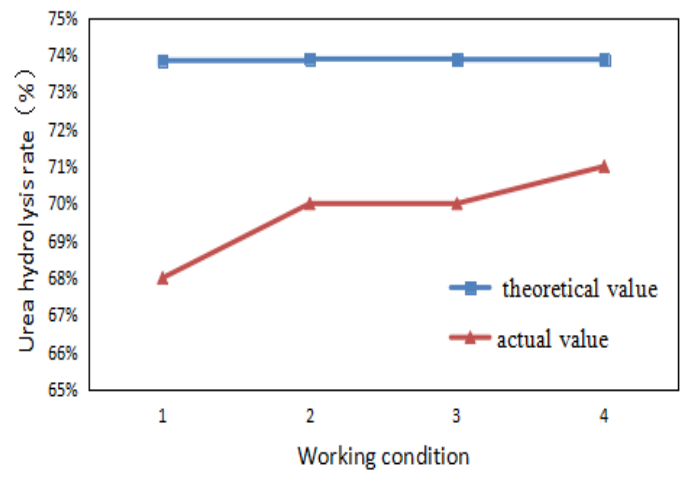

Figure 5. Comparison between theoretical value and experimental value of the rate of urea hydrolysis.

As can be seen from the figure 5, different initial mass of urea solution, in the same condition, the theoretical urea hydrolysis rate.is the same in the theory. This is because in the case of constant concentration, the urea hydrolysis rate is only related to the temperature, as shown in the formula of reaction rate constant [5], which has nothing to do with other factors. The urea hydrolysis rate of the experimental data was slightly lower than that of the theoretical data, and the value of the experimental data was slightly fluctuation. This is also caused by impurities in the urea and measuring errors in two ways. 


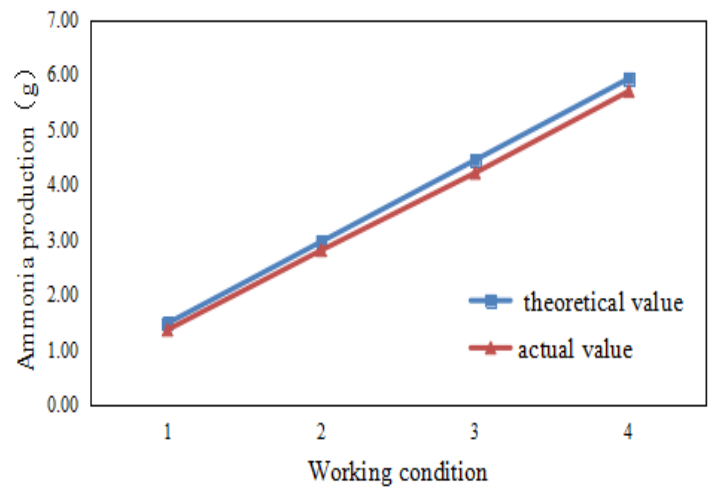

Figure 6. Comparison between theoretical value and experimental value of ammonia production.

As can be seen from the diagram, when the initial mass of the urea solution is increased, the yield of urea hydrolysis in the same condition is also increasing. After the $2 \mathrm{~min}$ hydrolysis, the ammonia yield of $10 \mathrm{ml}$ urea solution was $1.37 \mathrm{~g}$. With the continuous improvement of the quality of $20 \mathrm{ml}, 30 \mathrm{ml}, 40 \mathrm{ml}$, in the case of constant hydrolysis time, the amount of ammonia produced by urea hydrolysis reached $2.81 \mathrm{~g}, 4.22 \mathrm{~g}$ and $5.7 \mathrm{~g}$. Compared with the yield of $10 \mathrm{ml}$ urea solution, the amount of ammonia production increased by 2 times, 3 times and 4 times, respectively. In Figure 5 and figure 6, we can find that the higher the initial mass, the higher the initial quality, the higher the rate of urea hydrolysis. Therefore, under the condition of lower exhaust temperature, the urea solution can not be completely hydrolyzed, but the amount of ammonia required to complete hydrolysis can be achieved by increasing the initial mass of the urea solution.

\section{Conclusion}

(1)The ammonia reaction system of urea hydrolysis for vehicle belongs to the ACWU vapor liquid equilibrium system, and its thermodynamic simulation can be solved by extended UNIQUAC equation, modified Raoul equation, Henry equation and PHS equation of state. The calculated results of the method are in agreement with the experimental results, which can be used for the hydrolysis process of urea for vehicle.

(2)In the environment of urea hydrolysis for vehicle, the higher the hydrolysis temperature, the faster the hydrolysis of urea, and the faster the production of ammonia. Under the same conditions, the hydrolysis rate of urea is the same, the higher the initial quality, the more ammonia is produced.

(3)The reason of the error of the theory and the experiment mainly lies in the two aspects of the impurity and the measuring error in the urea.

\section{Acknowledgements}

This paper is supported by the National Natural Science Foundation of China(51306025) and the Fundamental Research Funds for the Central Universities(2572015AB13).

\section{References}

1. Zheng, Y., Luss, D., and Harold, M. SAE Int. J. Engines. 7, 3 (2014)

2. Sahu J N, Gangadharan P, Patwardhan A V, et a1. Ind. Eng. Che. Res. 48, 3 (2009)

3. Xiang K. Therm. Pwr. Gen. 40, 6 (2011)

4. Wei S., Yang N., Fu X., et al. Che. Eng. 39, 11 (2011)

5. Zhang S., Shao F., Wang N. Comput. Appl. Che. 30, 7 (2013) 